\title{
The Effectiveness of Barrage Use in Audio-visual Class of College English
}

\author{
Yonggang Zhao* \\ School of Foreign Languages \\ China West Normal University (CWNU) \\ Nanchong, China \\ zhyg007@163.com
}

\begin{abstract}
Barrage can be applied to teaching audio-visual courses because of its own features and its close connectivity with network teaching. This study provides an empirical study on the effectiveness of the audio-visual curriculum in college English. The research focuses on exploring whe ther the use of Barrage in audio-visual class outweighs the use of traditional listening teaching model and what attitudes learners adopt toward the use of Barrage in audio-visual class. The output as follows: the barrage use in audio-visual class outweighs the use of traditional listening teaching model. It can effectively stimulate students' interest, promote classroom interaction and facilitate teachers to monitor te aching.
\end{abstract}

Keywords-bullet screen teaching; audio-visual courses; college English; interaction

\section{INTRODUCTION}

With the continuous development of science and technology, network technology is also increasingly mature and as a new teaching way, network curriculum is gradually accepted by the learner. However, there are some shortcomings in network curriculum itself particularly shown in the restrictions of interaction between the student participation. Therefore, it is necessary to make a certain technical innovation and barrage technique just accords with this demand. Barrage is a social contact with video which is now popular on network and TV. Using it, many young people can comment to participate in interaction while they watch the internet and TV video. It is called "target" because of a vivid description about comments of timely roll and horizontally across the screen, like a curtain formed by intensive flying bullets. Barrage technology makes one-way communication process by "senders - information - medium - recipients effect" become more diverse and makes up for the shortcomings of network curriculum. Even though it is only used as tool of timely comments to improve user's interaction in video website, it can be combined with classroom teaching by which teachers can not only give timely monitoring to students' current knowledge in classroom teaching, but also can solve the difficulties students met in time, especially can make up for the disadvantages of less interaction in the network classroom between teachers and students. Based on this, the feasibility of barrage technology applied to English teaching will be discussed. According to our own teaching experience, we found that college English listening is the biggest barrier to hinder the non-professional students learning

The research is financed by Education Development Research Center of Sichuan Province (Project No. CJF14004)
English. Therefore, this paper will focus on the effectiveness of Barrage in audio-visual class on learners' listening comprehension.

\section{STATE OF THE ART}

"Barrage" which appeared first in the field of military, refers to that "use the intensive attacks on an area" ${ }^{11]}$. With the emergence of electronic shooting game, both players in the game hit each other through the bullets which look like a curtain, making the meaning of "barrage" extended into "dense bullets through the screen". The earliest Barrage video appeared from "niconico", a Japanese video website, which described "the phenomenon that a large number of comments displayed with subtitles appears on the screen at the same time like a flight shooting bullets" ${ }^{[2]}$. Unlike previous video website, "niconico" gives priority to push screen function by which at the same time of video playback, the user can release subtitles comments on the video screen and carry out the control on attributes of subtitles such as font and position. Most of the time, the audience's comments gradually slide across the screen from right to left and when a large number of comments appear on the screen at the same time, its effect looks just like dense bullets in the game. With the aid of barrage, viewers can freely comment at any time, and their comments can be visible to all audiences watching video right now. All this gives a feeling of watching movie with a lot of friends and improve the audience interactive experience by building the interaction scene of multiplayer online at the same time which meets the communication needs of the audience. "Niconico" is developing rapidly in Japan and it began to get profits from 2011.

In 2007, the first barrage video website named AcFun was established in China; our second one named Bilibili was built in 2009 which can absorb 350000 people online every day after 2010. Domestic mainstream video site "tudou" also launched the first interactive product of barrage "beans bubble" in August 2012. After two years of operation, at present the barrage technology has been applied to the total station and no less than 400000 users will choose to "open the barrage" to watch video every day. Because of young people's favor, barrage video has run quickly out of the network and gets full access to the mass communication field including 3d films, TV and so on. 
Despite the fact that barrage video has been much used in film, television, and other areas of the media and focuses on interaction between video and the audience, some researchers pointed out that the potential value of barrage video applied in the education field such as distance education, online learning education and so on should not be ignored. Taking online education for example, "as the main body of the online education, the students care much about how to turn the sense of face-to-face communication to online learning and barrage is the reality product of that idea of" ${ }^{\text {[3] }}$. In addition, "its strong interactivity can effectively help learners to alleviate the problems such as weak learning persistence, high dropout rates and lack of interaction" [4]. According to network video learning, as the recipient of video learning content, the learners not only lack of real-time interaction, but also hard to carry on diversified discussions for specific video content and communication. Therefore, "It can help designers or developers of online learning to provide a new way of video learning from another angle of view by exploring combining the barrage video with online video learning and making use of the powerful functions of barrage video to promote learners' online video interaction, learning experiences and develop more mature barrage video website" $[5]$. Recently, the barrage technology used in the actual classroom teaching has caused attention. One case is that Xiao-qiang zhang, a professor in Chongqing University who created a sensation by using target in teaching "network and new media". In media interview, he pointed out that barrage teaching is not only beneficial to the students attention to the teaching contents, more important it can improve classroom interaction and let more students actively participate in the interactive teaching by using barrage

\section{METHODOLOGY}

\section{A. Research Questions}

This study will focus on the effectiveness of Barrage in audio-visual class on learners' listening comprehension. The following two questions will be specifically discussed:

1) Does the use of Barrage in audio-visual class outweigh the use of traditional listening teaching model?

2) What are the Learners' attitudes toward the use of Barrage in audio-visual class?

\section{B. Participants}

The eighty sophomores from College of Chinese Language \& Literature and School of Educational Science of China West Normal University were recruited in the study. All these students are non-English majors who came from two classes (Class A and Class B) respectively and there are 40 students in each class.

\section{Instruments}

1) A pretest paper: aims at having a good knowledge of students' previous listening ability and check whether the two classes are at the same level.

2) A posttest paper: aims at comparing the results of the posttest in the experimental class with that in the control class in order to find out if there are differences of the listening ability between the two classes.

3) After the experiment, an anonymous questionnaire consisting of 15 items designed for exploring learners' attitudes toward the use of Barrage in audio-visual class.

\section{Tests data analysis and discussions}

\section{1) Pre-test data and discussions}

One pre-test has been carried out and the results of the two tests are shown in TABLE I.

From Table I, we can see the average scores of class A and class B are 17.48 and 17.45 which are similar, thereby indicating that the students' listening abilities are almost at same level. Although the average pretest score of class A is slightly higher than that of class B, but an independent sample $t$ test shows no evident difference between the two classes' average pretest scores $(\mathrm{t}=-0.33, \mathrm{P}=0.72>0.05)$. Thus, the results can support my following research.

TABLE I. INDEPENDENT SAMPLE T-TEST OF CLASS A AND B BEFORE THE EXPERIMENT

\begin{tabular}{|c|c|c|c|c|c|c|}
\hline \multirow{2}{*}{$\begin{array}{l}\text { Before the } \\
\text { Experiment }\end{array}$} & Class & $\mathrm{N}$ & Mean & $\begin{array}{c}\text { Std. } \\
\text { Deviation }\end{array}$ & $\mathrm{t}$ & Sig.(2-tailed) \\
\cline { 2 - 7 } & $\mathrm{A}$ & 40 & 17.48 & 3.578 & \multirow{2}{*}{0.33} & 0.972 \\
\cline { 2 - 7 } & $\mathrm{B}$ & 40 & 17.45 & 3.925 & & \\
\hline
\end{tabular}

2) Post-test data and discussions

Class A fell into the experimental class, whereas Class B fell into the controlled class, both of which were taught by the same teacher. During the experiment, the experimental class will apply Barrage in 1 listening teaching. At the same time, the control class will adopt the traditional model. The study lasts for 16 weeks. The post-test by SPSS is shown in Table2.

From TABLE II, it is clear to see that the average score of the experimental class $(M=19.71)$ is higher than that of the control class on English listening (17.97). The 2-tailed significance independent sample of the two classes is $0.009(0.009<0.05)$. And it indicates a statistically significant difference of the two classes. In other words, the improvement made by the experimental class is more significant than that of the control class. Therefore, a conclusion can be drawn that the Barrage use in audio-visual class outweighs the use of traditional listening teaching model.

TABLE II. INDEPENDENT SAMPLE T-TEST OF CLASS A AND B AFTER THE EXPERIMENT

\begin{tabular}{|c|c|c|c|c|c|c|}
\hline \multirow{4}{*}{ After the Experiment } & Class & $\mathrm{N}$ & Mean & Std. Deviation & $\mathrm{t}$ & Sig.(2-tailed) \\
\cline { 2 - 7 } & $\mathrm{A}$ & 40 & 19.71 & 2.470 & & \multirow{2}{*}{2.672} \\
\cline { 2 - 7 } & $\mathrm{B}$ & 40 & 17.97 & 3.075 & & \\
\hline
\end{tabular}

E. Questionnaire data and discussions

\section{1) Questionnaire design}

After the experiment, an anonymous questionnaire consists of five structural items (TABLE III) is used to explore learners' attitudes in the experimental class toward the use of Barrage in 
audio-visual class. In this survey, a total of 40 questionnaires were distributed to the students of the experimental class A. A total of 40 questionnaires were returned and all the questionnaires were valid.

TABLE III. QUESTIONNAIRE REGARDING THE STUDENTS’ FEEDBACK

\begin{tabular}{|c|c|c|c|c|c|}
\hline Item & Questions & \multicolumn{4}{|c|}{ Choices } \\
\hline 1 & Is the barrage use interesting? & Very interesting & Interesting & Not interesting & Do not know \\
\hline 2 & Is barrage use helpful to facilitate your classroom participation? & Very helpful & helpful & Not helpful & Do not know \\
\hline 3 & Is barrage use helpful for your listening comprehension? & Very helpful & helpful & Not helpful & Do not know \\
\hline 4 & Do you use barrage to actively interact? & Very active & Active & Inactive & Do not know \\
\hline 5 & Is barrage use beneficial to your deep understanding? & Very beneficial & beneficial & Not beneficial & Do not know \\
\hline
\end{tabular}

2) Questionnaire results and discussions

Item1: Is the barrage use interesting?

TABLE IV. THE QUESTION AND CHOICE OF ITEM 1

\begin{tabular}{|c|c|c|c|c|}
\hline Question & \multicolumn{4}{|c|}{ Choices } \\
\hline Item1 & $\begin{array}{c}\text { Very } \\
\text { interesting }\end{array}$ & Interesting & $\begin{array}{c}\text { Not } \\
\text { interesting }\end{array}$ & $\begin{array}{c}\text { Do not } \\
\text { know }\end{array}$ \\
\hline $\mathrm{N}$ & 25 & 10 & 2 & 3 \\
\hline Percentage & $62.5 \%$ & $25.0 \%$ & $5.0 \%$ & $7.5 \%$ \\
\hline
\end{tabular}

When asked the question of item1, the data above shows that 25 students think it is very interesting which occupy $62.5 \%$ of all the participants, and 10 students think that it is interesting which occupy $25.0 \%$. Only 2 students think it is not interesting, and one student does not know whether the barrage use is interesting. That is to say, most students, up to 87.5\%, show their interests to the barrage use.

Item2: Is barrage use helpful to facilitate your classroom participation?

TABLE V. THE QUESTION AND CHOICE OF ITEM 2

\begin{tabular}{|c|c|c|c|c|}
\hline Question & \multicolumn{4}{|c|}{ Choices } \\
\hline Item2 & Very helpful & helpful & Not helpful & Do not know \\
\hline N & 20 & 10 & 5 & 5 \\
\hline Percentage & $50 \%$ & $25 \%$ & $12.5 \%$ & $12.5 \%$ \\
\hline
\end{tabular}

About the question of item2, the data above shows that 20 students with the proportion of $50 \%$ of the participants think that it is very helpful and 10 students with the proportion of $25 \%$ think it is helpful. Only 5 students think that it is not helpful and 5 students doesn't know whether the barrage use is helpful. The proportion of the participants who think that barrage use is helpful to facilitate classroom participation is up to $75 \%$.

Item3: Is barrage use helpful for your listening comprehension?

TABLE VI. THE QUESTION AND CHOICE OF ITEM 3

\begin{tabular}{|c|c|c|c|c|}
\hline Questions & \multicolumn{4}{|c|}{ Choices } \\
\hline Item3 & Very helpful & helpful & Not helpful & Do not know \\
\hline $\mathrm{N}$ & 18 & 13 & 5 & 4 \\
\hline Percentage & $45 \%$ & $32.5 \%$ & $12.5 \%$ & $10 \%$ \\
\hline
\end{tabular}

With regard to the question item3, the data above show that 18 students, amount to $45 \%$, believe that barrage use is helpful for listening comprehension, and 13 students, amount to $32.5 \%$, think that it is helpful. Only 5 students think that the platform is unnecessary, and 4 students do not know whether the platform is necessary for them.
Item4: Do you use barrage to actively interact?

TABLE VII. THE QUESTION AND CHOICE OF ITEM 4

\begin{tabular}{|c|c|c|c|c|}
\hline Questions & \multicolumn{4}{|c|}{ Choices } \\
\hline Item4 & Very active & Active & Inactive & Do not know \\
\hline $\mathrm{N}$ & 15 & 15 & 6 & 4 \\
\hline Percentage & $37.5 \%$ & $37.5 \%$ & $15 \%$ & $10 \%$ \\
\hline
\end{tabular}

Concerns about the question item4, there are altogether 30 students with the proportion of $75 \%$ show positive attitudes from the above table among which $37.5 \%$ think they are "very active" and $37.5 \%$ think they are "active". The number of the students who think they are "inactive" or "do not know" is 10 with the proportion of $25 \%$ altogether, and $15 \%$ and $10 \%$ separately.

Item5: Is barrage use beneficial to your deep understanding?

TABLE VIII. THE QUESTION AND CHOICE OF ITEM 5

\begin{tabular}{|c|c|c|c|c|}
\hline Questions & \multicolumn{4}{|c|}{ Choices } \\
\hline Item5 & Very beneficial & beneficial & Not beneficial & Do not know \\
\hline $\mathrm{N}$ & 10 & 17 & 6 & 7 \\
\hline Percentage & $25 \%$ & $42.5 \%$ & $15 \%$ & $17.5 \%$ \\
\hline
\end{tabular}

When talked about the question item5, there are 10 students, $25 \%$ of the participants confirmed that barrage use is "very helpful", and 17 students, $42.5 \%$ of the participants stated that barrage use is helpful, only 6 students answered that it's not beneficial, and 7 stated that they do not know which occupy $15 \%$ and $17.5 \%$ separately.

\section{F. Interview}

After the experiment, an interview is conducted on the subjects in experiment class to know their evaluations towards target use. It is also hoped to find out some information about why they show the attitudes in the experiment above. The question is: What is your evaluation about the barrage use in audio-visual class? Some answers are listed:

(1) It can bring visual feeling to students just like watching a movie with friends.

(2) It can help students to ask for help in time.

(3) It provides more chance for students to answer questions.

(4) Poor students can use barrage in a hidden way to put forward ideas without fear or shyness.

(5) The interaction is convenient and effective.

(6) Students can understand the learning contents more deeply by a lot of interactions. 
(7) It's convenient for teacher to remind students when they are absent-minded.

(8) Teacher can learn students' learning situation timely and accurately.

\section{CONCLUSION}

Barrage technology provides a new orientation for teaching. Because audio-visual course has a great deal connectivity with network teaching, it provides more possibilities of integration. The experimental results show that application of barrage in the audio-visual classroom teaching is very effective. It not only plays great role in promoting learners' enthusiasm, arousing their interests, deepening the classroom interaction but also brings convenience for teachers to monitor the learning process, collect learning data and improve teaching efficiency. Its validity of the barrage teaching stems can mainly be summarized as follows:

Firstly, Instant interaction improves student engagement and motivation.

By the barrage technology, the students' questions or ideas will be real-time displayed on video screen through a barrage and it won't conflict with the process of watching the video. This kind of instant and direct presentation through barrage makes communications more real-time and interactive. Therefore, the characteristics of barrage use can induce students' learning motivation, increase their interest in learning, and it also greatly improves their participation.

Secondly, it can deepen the classroom interaction among the subjects.

On the one hand, it can deepen the interaction between teachers and students. The teacher can raise specific questions or expand contents through the barrage in the teaching key or difficult language points and the students can participate in discussions and answering or asking questions by the contents listed on the view screen. The whole teaching or learning can be realized by face-to-face interaction without deviating from video which can enhance the teachers and students' sense of immediacy. On the other hand, it can deepen peer interaction. First, students can collaborate and learn from the bullet screen. For example, after the teacher issues a task in group unit, the group leader can organize the arguments of the group members through the bullet screen and learn from each other. At the same time, different students can conduct real-time discussion on one of the knowledge points in video, and the partner can answer questions and discuss different methods or ideas. Because the publisher's name is hidden, students can boldly present their own questions and ideas without feeling scared or shy. This real-time peer exchange creates an atmosphere of face-to-face learning for students and promotes the progress of learning. In addition, students can also share their learning resources and experiences with the help of bullets.

Thirdly, it is helpful to strengthen the deep learning of video content.

The comments from video of the bullet screen are specific, diversified and fragmented, so the students' understanding can be deepened when they see the targeted comments in the process of learning video. At the same time, because different students give different comments by barrage and every student is a information source, the decentralized information makes the learners' understanding of the content of the video is more diversified. The students can deepen the study of video content by integrating the barrage information of others and with their own views. In addition, the fragmentation of the barrage information is also the deconstruction of video content on the basis of the changes of video time and content which deepens students' understanding of each knowledge point.

Fourthly, it is beneficial to the participation of the students with low language level.

On the one hand, it can help provide comprehensible input. In traditional video teaching, the student can't concentrate if meet difficulty. Yet when video is added to the function of sending the bullet screen, they can always turn to their teachers and peers for help, thus, they can get help in time to overcome difficulties and continue to learn. On the other hand, for some learning tasks, it is difficult to use full of discussion or comment for some students with low level of language. Yet using bullet screen, teachers can encourage them send simplified barrage content, or even use some designed symbols or characters to replace the multifarious words, then slowly build up confidence in the process of constant participation and improve their level of language in the end.

\section{In addition, it is helpful to monitor the learning process.}

Monitoring learning mainly refers to that the teacher can learn the students' learning situation by their barrage comments Using barrage, the teacher can not only monitor the individual status but also grasp the whole learners group's learning state and help them adjust by giving tips, advice and guidance.

Lastly, it can provide analytical data about learning. The barrage can help the teacher get learners' data about their learning. Teachers can learn the difficulties the learners met and their learning situation by observing the content sent by the learning. At the same time, teachers can grasp the students' learning status and effect by learning the time and frequency of the barrage information sent by the learners. Any more, the teacher can master all kinds of information including emotion, attitude, values and others by sorting and analyzing the collected information from the barrage.

\section{REFERENCES}

[1] H. F. Chen \& S. Z. Feng, “Action mechanis m of flipped classroom in Chinese international fundamental education,” Modern Chinese, No.4, p5, 2015.

[2] K.S. Li, "Digital transformation research of foreign Chinese education," Publishing Research, No.2, p45, 2016.

[3] J.L \& X. M. Zhang, “Application of bullet in online education,” Journal of Fujian Radio and Television University, No.1, p5, 2015.

[4] J.D. Wang, Y.Y. Feng \& Y.Wang, “Cold thinking behind the MOOC," Educational Research, No.9 ,p104,2014.

[5] H.F.Li \& W. Wang, "Bullet screen video: new orientation of online video interactive learning,” Modern Education Technology, No.6, P12,2015.

[6] http://mt.sohu.com/20160526/n451593494.shtml 